\title{
FORMULATION OF GLIMEPIRIDE AND ATORVASTATIN CALCIUM NANOPARTICLES BY LIQUID ANTISOLVENT PRECIPITATION METHOD THROUGH DOUBLE STEP COMMINUTION TECHNIQUE AND ITS EVALUATION
}

\author{
VISHAL S REDDY, GOWDA DV*, VISHAL GUPTA N, MAHENDRAN B \\ Department of Pharmaceutics, JSS College of Pharmacy, Sri Shivarathreeshwara Nagara, Mysuru, Karnataka, India. \\ Email: dvgowda@jssuni.edu.in
}

Received: 16 February 2019, Revised and Accepted: 10 April 2019

\begin{abstract}
Objective: The present research is to formulate glimepiride and atorvastatin calcium nanoparticles for the type 2 diabetes mellitus for the improvement of glucose tolerance associated with dyslipidemia formulated by liquid antisolvent (LAS) precipitation technique.

Method: Glimepiride nanoparticles and atorvastatin calcium nanoparticles were prepared using a LAS precipitation technique. Solvent-to-antisolvent ratio used was 3.5:6.5 and 2.5:7.5 and the drug concentration used was $40 \mathrm{mg} / \mathrm{ml}$ and $60 \mathrm{mg} / \mathrm{ml}$, respectively.

Results: The X-ray diffraction was determined, and the data of the optimized glimepiride formulation revealed that the prepared nanosized glimepiride powder was existed in crystalline form. The percentage yield for the formulations of glimepiride and atorvastatin calcium nanoparticles was found to be $72.8 \pm 1.8 \%$ and $75.3 \pm 2.2 \%$, respectively. In vivo studies in albino Wistar rats demonstrated that the $\mathrm{C}_{\max }$ and $\mathrm{AUC}_{0-24 \mathrm{~h}}$ of optimized glimepiride and atorvastatin calcium nanosized formulation were found to be $24,451.14 \pm 2170.5 \mathrm{ng} / \mathrm{ml}$ and $162,945.12 \pm 241.5 \mathrm{ng} / \mathrm{ml}$ and $1385.43 \pm 153.3 \mathrm{ng} / \mathrm{ml}$ and $3636.57 \pm 65.2 \mathrm{ng} / \mathrm{ml}$, respectively. Dissolution study of optimized formulations shows that marked enhancement in dissolution rate compared to pure one. The stability studies of the mixture of glimepiride and atorvastatin calcium powder when stored at $4 \pm 3^{\circ} \mathrm{C}$ refrigerated temperature have shown no significant changes in physical appearance, drug content, particle size, and polydispersity index (PDI). Conversely, the sample stored at room temperature has shown a significant increase in particle size and PDI, with no significant changes in drug content and physical appearance.
\end{abstract}

Conclusion: The formulation of glimepiride and atorvastatin calcium drug nanoparticles shows an increase in the surface-to-volume ratio of active pharmaceutical ingredient, resulting in better drug solubility and hence increasing the bioavailability when compared to its pure form.

Keywords: Atorvastatin calcium, Antisolvent, Glimepiride, Hydroxypropyl methylcellulose, Nanoparticles.

(C) 2019 The Authors. Published by Innovare Academic Sciences Pvt Ltd. This is an open access article under the CC BY license (http://creativecommons. org/licenses/by/4. 0/) DOI: http://dx.doi.org/10.22159/ajpcr.2019.v12i5.32632

\section{INTRODUCTION}

Nanotechnology has brought a range of novel promises into biological discovery and medical practice. Nanoparticulate drug delivery is a revolutionized drug delivery which allows therapeutic agents to be selectively targeted for organs, tissues, and cell, minimizes exposure of healthy tissues to drugs. Here, the drug particle size is reduced to nanometer scale, leading to an increase in the surface-to-volume ratio of active pharmaceutical ingredient (API), resulting in better drug solubility and hence increasing the bioavailability $[1,2]$.

Diabetes mellitus is a group of metabolic disorders, wherein the body is exposed to high blood sugar for a prolonged period. It is due to either the pancreas not producing enough insulin or the cells of the body not responding properly to the insulin produced [3]. Dyslipidemia is a condition in which abnormal amount of lipids such as triglycerides, cholesterol, or fat phospholipids is seen in the blood. Atorvastatin calcium is used as lipid-lowering agent in the prevention of dyslipidemia [4]. Glimepiride1-[[p-[2-(3-ethyl-4-methyl-2-oxo-3-pyrroline-1-carboxamido)ethyl] phenyl] sulfonyl]-3-(trans-4-methylcyclohexyl) urea is a new oral sulfonylurea hypoglycemic agent for the treatment of non-insulindependent (type 2) diabetes mellitus [5], and its mode of action is to increase insulin production by the pancreas [6].

Atorvastatin calcium is a white to off-white crystalline powder that is insoluble in aqueous solutions of $\mathrm{pH} 4$ and below, and it is very slightly soluble in distilled water. Atorvastatin is a member of the drug class known as statins, which is used as a lipid-lowering agent and for prevention of events associated with cardiovascular disease. It also stabilizes plaque and prevents strokes through anti-inflammatory and other mechanisms [7]. Like all statins, atorvastatin works by inhibiting 3-hydroxy-3-methylglutaryl coenzyme A reductase, an enzyme found in liver tissue that plays a key role in the production of cholesterol in the body.

Patients diagnosed with type 2 diabetes in which prolonged elevation of insulin levels can lead to dyslipidemia or diagnosed with cardiovascular disease. Approximately one-half of patients with type 2 diabetes die prematurely due to cardiovascular disorders. Hence, a combination of glimepiride and atorvastatin calcium formulation is chosen to avoid such cardiovascular disorders $[8,9]$

The novel double step comminution technique ensures generation of ultrafine nanoparticles when applied with liquid antisolvent (LAS) precipitation method. This technique is simple, robust, cost-effective, and reproducible method for formulating particulate drug delivery systems.

Based on these properties, the ultrafine glimepiride and atorvastatin calcium drug nanoparticles were successfully prepared by LAS precipitation technique.

\section{MATERIALS AND METHODS}

\section{Materials}

Glimepiride was purchased as Azulix from Torrent Pharmaceuticals Ltd, and atorvastatin calcium API was purchased from Afton Pharma; acetone, hydroxypropyl methycellulose K15M (HPMC), mannitol, polyvinyl pyrrolidone (PVP), and polyethylene glycol (PEG) were 
purchased from Loba Chemie, Mumbai. All other chemicals and buffers used were of analytical grade.

\section{Preformulation studies}

Solubility [10]

Solubility of glimepiride and atorvastatin calcium was Studied by dissolving the glimepiride drug in phosphate buffer of $\mathrm{pH} 1.2,6.8,7.2$, acetone, methanol, ethanol, and dimethyl sulfoxide (DMSO).

Drug excipient compatibility [10]

The compatibility between the drug and polymer was studied by Fourier-transform infrared spectroscopy (FT-IR) technique. The position of peaks in FT-IR spectra of pure glimepiride and atorvastatin was compared with those in FT-IR spectra of glimepiride and atorvastatin with their excipients.

\section{Methods}

Development of glimepiride nanoparticles and atorvastatin calcium nanoparticles: Optimization of solvent-to-antisolvent ratio $[10,11]$

Initially, the effect of solvent-to-antisolvent ratio was investigated using different volume ratios. Here, the different batches were prepared by mixing drug solution with antisolvent by applying mixing forces, and the different acetone to water volume ratios are mentioned in Table 1 . During the entire study, the drug concentration $(50 \mathrm{mg} / \mathrm{ml})$, homogenization speed (5000 rpm), and homogenization time (5 min) were kept constant.

\section{Optimization of drug concentration [10,11]}

The effect of drug concentration was investigated. Here, various glimepiride solutions and atorvastatin calcium solutions were prepared in acetone in the concentration range of $10-60 \mathrm{mg} / \mathrm{ml}$ and $10-70 \mathrm{mg} / \mathrm{ml}$, respectively. Different batches of nanoparticles were prepared by mixing the above prepared drug solutions with antisolvent by applying mixing forces. During the entire study, the solvent-to-

Table 1: Optimization of solvent-to-antisolvent ratio

\begin{tabular}{llll}
\hline S. No. & Acetone $(\mathrm{ml})$ & Water $(\mathrm{ml})$ & Appearance \\
\hline 1 & 5 & 5 & No uniformity \\
2 & 4.5 & 5.5 & No uniformity \\
3 & 4 & 6 & No uniformity \\
4 & 3.5 & 6.5 & $\begin{array}{l}\text { Solid uniform sized } \\
\text { nanoparticles }\end{array}$ \\
& & & No uniformity \\
5 & 3 & 7 & Solid uniform sized \\
6 & 2.5 & 7.5 & nanoparticles \\
& & & No uniformity \\
7 & 2 & 8 & No uniformity \\
8 & 1.5 & 8.5 & No uniformity \\
9 & 1 & 9 & \\
\hline
\end{tabular}

antisolvent ratio of glimepiride was (3.5:6.5), atorvastatin calcium (2.5:7.5)with their homogenization speed (5000 rpm) were kept at constant rate.

Formulation of glimepiride nanosuspension and atorvastatin calcium nanosuspension [10-12]

Glimepiride nanoparticles and atorvastatin calcium nanoparticles were prepared using a LAS precipitation technique. Solvent-to-antisolvent ratio used was 3.5:6.5 and 2.5:7.5 and the drug concentration used was $40 \mathrm{mg} / \mathrm{ml}$ and $60 \mathrm{mg} / \mathrm{ml}$, respectively. Initially, the glimepiride was dissolved in $35 \mathrm{ml}$ and atorvastatin calcium was dissolved in $25 \mathrm{ml}$ of acetone using sonication, and then, the obtained solution was filtered separately through a $0.22 \mu$ Whatman filter paper to remove possible particulate impurities. The above prepared glimepiride solution was drained into the $65 \mathrm{ml}$ and atorvastatin calcium into $75 \mathrm{ml}$ of different aqueous solutions of HPMC K15M/lactose prepared in concentrations of $0.1,0.2,0.3,0.4,0.5$, and $0.6 \% \mathrm{w} / \mathrm{v}$, which was previously cooled in an ice water bath with constant homogenization (Polytron PT 1600E, Switzerland) at 20,000 and 15,000 rpm, respectively, for $5 \mathrm{~min}$, ensuring the formation of suspension. Further, in the second step of comminution, the suspension was probe sonicated (Sonics and Materials Inc., Vibra Cell, Model VCX 750, Connecticut, USA) with a tip diameter of $13 \mathrm{~mm}$, immersed $10 \mathrm{~mm}$ deep in the liquid suspension for another $10 \mathrm{~min}$. The formed dispersion was immediately centrifuged, and the residue was redispersed in fresh distilled water with sonication. The process was repeated twice and the final dispersion was subjected to lyophilization. Different formulations were prepared by changing the amount of the ingredients as shown in Tables 2 and 3 for glimepiride nanosuspension and atorvastatin calcium nanosuspension, respectively.

\section{Lyophilization of nanosuspension [12]}

From the above-obtained glimepiride (GD-3 and GD-10) and atorvastatin (AC-4 and AC-9) nanosuspension, the batches resulted with lowest particle size between each formulation were selected for further lyophilization studies. Accurately 1\%, 2\%,3\%, 4\%, and $5 \% \mathrm{w} / \mathrm{v}$ mannitol as cryoprotective was added into the above-prepared nanosuspension formulations separately before deep freezing. The nanosuspensions were filled into vials with rubber stopper and frozen using deep freezer (Remi PVD-185 D, India) at $-40^{\circ} \mathrm{C}$ for $24 \mathrm{~h}$. Then, the vials were transferred into a freeze dryer (Ilshin Laboratory Co Ltd., Korea) at $40^{\circ} \mathrm{C}$ for $24 \mathrm{~h}$. Formulations were prepared by changing the concentration of cryoprotectant as shown in Tables 4 and 5 .

\section{EVALUATION STUDIES [8,10-16]}

\section{Percentage yield}

The obtained glimepiride nanoparticles were dried at room temperature and weighed. The percentage yield of the obtained formulation was calculated by the given formula.

$$
\text { Percentage yield }=\frac{\text { Actual } \text { yield }}{\text { Theoretical yield }} \times 100
$$

Table 2: Formulation chart of glimepiride nanosuspension

\begin{tabular}{lllll}
\hline Formulation code & Solvent-to-antisolvent ratio & Drug concentration $\mathbf{( m g} / \mathbf{m l})$ & Stabilizer & Stabilizer concentration $\% \mathbf{~ ( w / v ) ~}$ \\
\hline GD-1 & 40 & HPMC K15M & 0.1 \\
GD-2 & & & HPMC K15M & 0.2 \\
GD-3 & & & HPMC K15M & 0.3 \\
GD-4 & & HPMC K15M & 0.4 \\
GD-5 & & HPMC K15M & 0.5 \\
GD-6 & & HPMC K15M & 0.6 \\
GD-7 & & Lactose & 0.1 \\
GD-8 & & Lactose & 0.2 \\
GD-9 & & Lactose & 0.3 \\
GD-10 & & Lactose & 0.4 \\
GD-11 & & Lactose & 0.5 \\
GD-12 & & Lactose & 0.6 \\
\hline
\end{tabular}

HPMC: Hydroxypropyl methycellulose 
Table 3: Formulation chart of atorvastatin calcium nanosuspension

\begin{tabular}{|c|c|c|c|c|}
\hline Formulation code & Solvent-to-antisolvent ratio & Drug concentration $(\mathrm{mg} / \mathrm{ml})$ & Stabilizer & Stabilizer concentration $\%(w / v)$ \\
\hline AC-1 & $2.5: 7.5$ & 60 & PVP & 0.1 \\
\hline $\mathrm{AC}-2$ & & & PVP & 0.2 \\
\hline $\mathrm{AC}-3$ & & & PVP & 0.3 \\
\hline AC-4 & & & PVP & 0.4 \\
\hline AC-5 & & & PVP & 0.5 \\
\hline AC-6 & & & PEG 4000 & 0.1 \\
\hline AC-7 & & & PEG 4000 & 0.2 \\
\hline AC-9 & & & PEG 4000 & 0.4 \\
\hline $\mathrm{AC}-10$ & & & PEG 4000 & 0.5 \\
\hline
\end{tabular}

PEG: Polyethylene glycol, PVP: Polyvinylpyrrolidone

Table 4: Lyophilization of glimepiride nanosuspension with varied concentration of cryoprotectant

\begin{tabular}{ll}
\hline Formulation code & Concentration of cryoprotectant $\% \mathbf{w} / \mathbf{v})$ \\
\hline GD-3a & 0 \\
GD-3b & 1 \\
GD-3c & 2 \\
GD-3d & 3 \\
GD-3e & 4 \\
GD-3f & 5 \\
GD-10a & 0 \\
GD-10b & 1 \\
GD-10c & 2 \\
GD-10d & 3 \\
GD-10e & 4 \\
GD-10f & 5 \\
\hline
\end{tabular}

Table 5: Lyophilization of atorvastatin calcium nanosuspension with varied concentration of cryoprotectant

\begin{tabular}{ll}
\hline Formulation code & Concentration of cryoprotectant $\%(w / v)$ \\
\hline AC-4a & 0 \\
AC-4b & 1 \\
AC-4c & 2 \\
AC-4d & 3 \\
AC-4e & 4 \\
AC-9a & 0 \\
AC-9b & 1 \\
AC-9c & 2 \\
AC-9d & 3 \\
AC-9e & 4 \\
\hline
\end{tabular}

\section{Particle size and size distribution}

The particle size and size distribution of obtained formulations were studied using scanning electron microscopy (SEM) technique.

\section{Drug content}

Drug-loaded nanoparticles were weighed, then grinded to fine powder, and dissolved in a solvent in which the drug is completely soluble. It was subjected to stirring around $700 \mathrm{rpm}$ for $3 \mathrm{~h}$. Amount of drug in the supernatant was determined by UV-spectrophotometric method.

\section{X-ray diffraction (XRD) studies}

The X-ray diffractogram of glimepiride API was studied, and it shows characteristic sharp and intense peaks indicating its crystalline nature.

\section{In vitro drug release}

The pure APIs and prepared drug nanoparticles were mixed together in fixed dose combination and filled in a single hard gelatin capsule and evaluated for in vitro drug release study.

\section{In vivo studies}

The mean plasma concentration-time profile of glimepiride API coadministered with atorvastatin calcium API and nanosized
Table 6: Solubility of glimepiride and atorvastatin

\begin{tabular}{lll}
\hline \multirow{2}{*}{ Solvent } & Solubility & \\
\cline { 2 - 3 } & Glimepiride & Atorvastatin \\
\hline Phosphate buffer pH 1.2 & $5.2 \mathrm{mg} / \mathrm{L}$ & $6.84 \mathrm{~g} / \mathrm{L}$ \\
Phosphate buffer pH 6.8 & $18.4 \mathrm{mg} / \mathrm{L}$ & $214.6 \mathrm{~g} / \mathrm{L}$ \\
Phosphate buffer pH 7.2 & $23.5 \mathrm{mg} / \mathrm{L}$ & $287.4 \mathrm{~g} / \mathrm{L}$ \\
Acetone & $7.3 \mathrm{gm} / \mathrm{L}$ & $198.7 \mathrm{~g} / \mathrm{L}$ \\
Methanol & $389.4 \mathrm{mg} / \mathrm{L}$ & $232.1 \mathrm{~g} / \mathrm{L}$ \\
Ethanol & $4.8 \mathrm{gm} / \mathrm{L}$ & $21.6 \mathrm{~g} / \mathrm{L}$ \\
DMSO & $25.1 \mathrm{gm} / \mathrm{L}$ & $103.8 \mathrm{~g} / \mathrm{L}$ \\
\hline
\end{tabular}

DMSO: Dimethyl sulfoxide

glimepiride formulation (GD-3d) coadministered with nanosized atorvastatin calcium formulation (AC-4d) were studied, and the corresponding pharmacokinetic parameters are summarized.

\section{Stability studies}

Stability studies of optimized fixed dose combination formulation of nanosized glimepiride (GD-3d batch) and atorvastatin calcium (AC- $4 \mathrm{~d}$ batch) were carried out at $25 \pm 2^{\circ} \mathrm{C} / 60 \pm 5 \% \mathrm{RH}$ and $4 \pm 3^{\circ} \mathrm{C}$. The formulations were subjected to various evaluation parameters such as physical appearance, particle size, polydispersity index (PDI), and drug content.

\section{RESULTS AND DISCUSSION}

Preformulation studies

Solubility

The solubility of glimepiride and atorvastatin calcium was studied using different phosphate buffers of $\mathrm{pH} 1.2,6.8,7.2$, acetone, methanol, ethanol, and DMSO as shown in Table 6.

\section{Drug excipient compatibility}

\section{FT-IR studies of glimepiride and their formulation excipients}

FT-IR spectral analysis indicated that the characteristic absorption peaks present in the IR spectra of glimepiride drug substance were also found in the physical mixtures of the polymers used (HPMC K15M/lactose/ mannitol) without any appreciable change in the position, attributing to the compatibility of drug-polymer. Hence, it can be concluded that drug can be used with the above-selected polymers without causing instability in the formulation. Characteristic IR absorption peaks are shown in Table 7 and Fig. 1.

FT-IR studies of atorvastatin calcium and their formulation excipients

FT-IR spectral analysis indicated that the characteristic absorption peaks present in the IR spectra of atorvastatin calcium drug substance were also found in the physical mixtures of the polymers used (PVP/ PEG 4000/mannitol) without any appreciable change in the position, attributing to the compatibility of drug-polymer. Hence, it can be concluded that drug can be used with the above-selected polymers 
Table 7: Characteristic IR absorption peaks

\begin{tabular}{|c|c|c|c|}
\hline \multirow[t]{2}{*}{ Wave number of drug (Glimepiride pure drug) } & \multicolumn{3}{|c|}{ Wave number $\left(\mathrm{cm}^{-1}\right)$ of the physical mixture } \\
\hline & (Glimepiride+HPMC K15M) & (Glimepiride+lactose) & (Glimepiride+mannitol) \\
\hline $3119.00 \mathrm{~cm}^{-1}(\mathrm{~N}-\mathrm{H}$ stretching $)$ & 3118.11 & 3118.05 & 3118.58 \\
\hline $2854.74 \mathrm{~cm}^{-1}$ (O-H stretching) & 2853.56 & 2853.75 & 2851.05 \\
\hline $1525.74 \mathrm{~cm}^{-1}(\mathrm{~N}=0$ stretching $)$ & 1529.40 & 1526.74 & 1526.46 \\
\hline $1157.33 \mathrm{~cm}^{-1}$ (C-N stretching) & 1158.31 & 1158.33 & 1158.33 \\
\hline
\end{tabular}

HPMC: Hydroxypropyl methycellulose, IR: Infrared spectroscopy

Table 8: Characteristic IR absorption peaks

\begin{tabular}{|c|c|c|c|}
\hline \multirow[t]{2}{*}{ Wave number of drug (atorvastatin calcium) } & \multicolumn{3}{|c|}{ Wave number $\left(\mathrm{cm}^{-1}\right)$ of the physical mixture } \\
\hline & $\begin{array}{l}\text { (Atorvastatin } \\
\text { calcium+PVP) }\end{array}$ & $\begin{array}{l}\text { (Atorvastatin } \\
\text { calcium+PEG 4000) }\end{array}$ & $\begin{array}{l}\text { (Atorvastatin } \\
\text { calcium+mannitol) }\end{array}$ \\
\hline $2922.25 \mathrm{~cm}^{-1}$ (Aliphatic C-H stretching) & 2910.58 & 2912.25 & 2910.44 \\
\hline $1651.12 \mathrm{~cm}^{-1}(\mathrm{C}=0$ stretching $)$ & 1647.23 & 1651.94 & 1649.64 \\
\hline $1577.82 \mathrm{~cm}^{-1}(\mathrm{C}=\mathrm{C}$ bending $)$ & 1567.82 & 1566.16 & 1567.06 \\
\hline $1159.92 \mathrm{~cm}^{-1}(\mathrm{O}-\mathrm{H}$ bending) & 1159.42 & 1159.92 & 1159.90 \\
\hline
\end{tabular}

PEG: Polyethylene glycol, PVP: Polyvinyl pyrrolidone, IR: Infrared spectroscopy

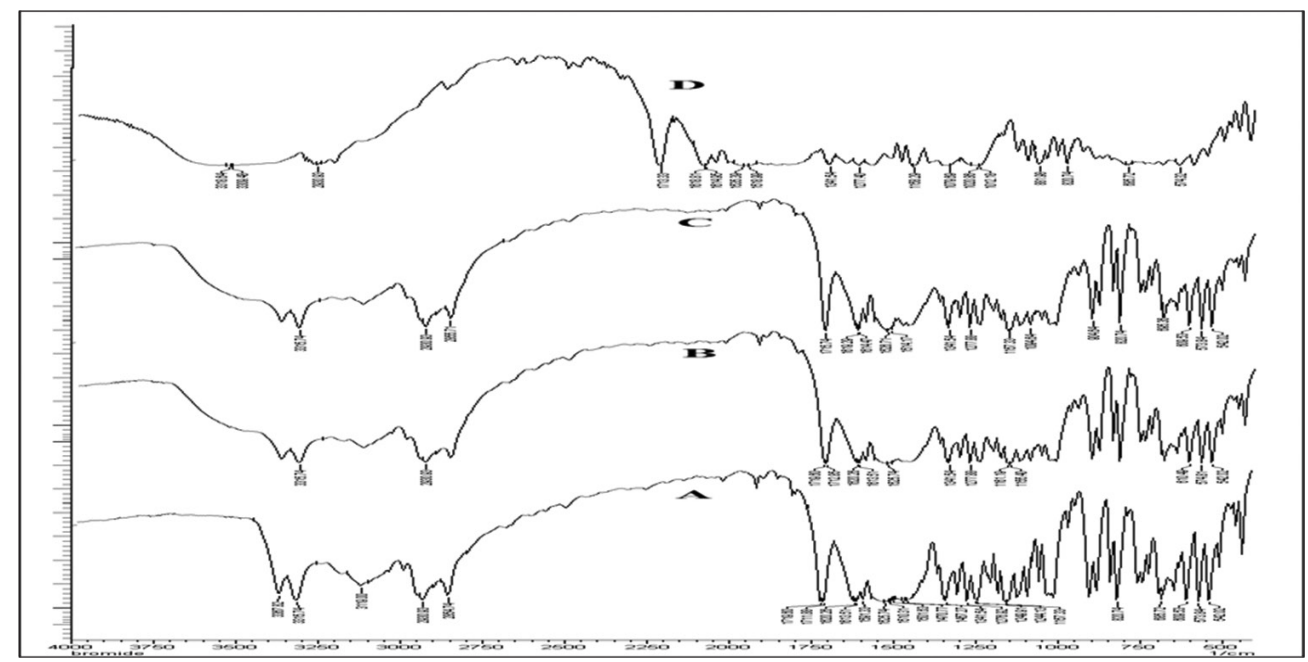

Fig. 1: Fourier-transform infrared spectroscopy spectra of: (A) glimepiride pure drug; (B) glimepiride+hydroxypropyl methycellulose K15M; (C) glimepiride+lactose; (D) glimepiride+mannitol

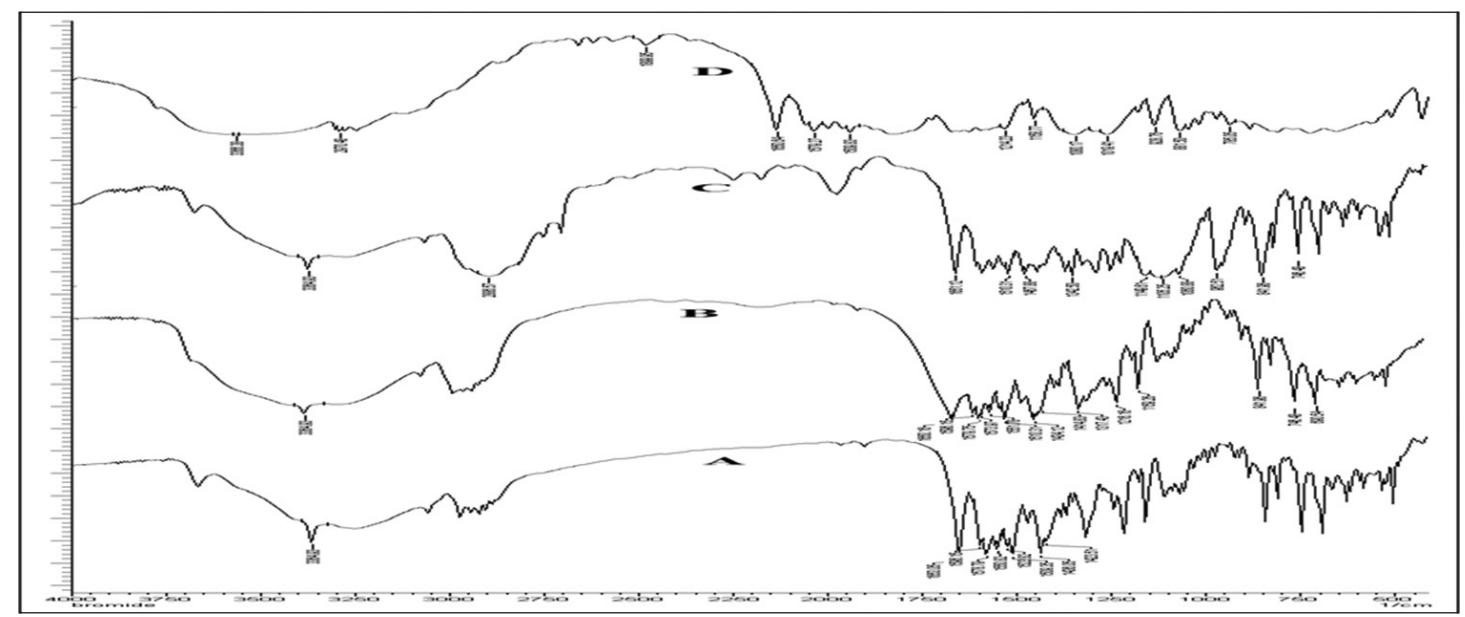

Fig. 2: Fourier-transform infrared spectroscopy spectra of: (A) atorvastatin calcium; (B) atorvastatin calcium+polyvinyl pyrrolidone; (C) atorvastatin calcium+polyethylene glycol 4000; (D) atorvastatin calcium+mannitol 
Table 9: Glimepiride nanoparticle formulations practical yield

\begin{tabular}{llll}
\hline Formulation code & Total amount of drug and excipients added (mg)* & Practical yield (mg)* $^{*}$ & Percentage yield (\%)* $^{*}$ \\
\hline GD-3d & 2300 & $1652.0 \pm 21.3$ & $72.8 \pm 1.8$ \\
GD-10f & 2800 & $2054.2 \pm 26.5$ & $73.4 \pm 2.3$ \\
\hline
\end{tabular}

*mean \pm SD n=3

Table 10: Atorvastatin calcium nanoparticle formulation practical yield

\begin{tabular}{llll}
\hline Formulation code & Total amount of drug and excipients added (mg)* & Practical yield (mg)* & Percentage yield (\%)* \\
\hline AC-4d & 2500 & $1906.5 \pm 18.3$ & $75.3 \pm 2.2$ \\
AC-9c & 2300 & $1676.4 \pm 20.8$ & $73.8 \pm 2.7$ \\
\hline
\end{tabular}

*mean \pm SD $n=3$

without causing instability in the formulation. Characteristic IR absorption peaks are shown in Table 8 and Fig. 2.

Development of glimepiride nanoparticles and atorvastatin calcium nanoparticles

Optimization of solvent-to-antisolvent ratio

Optimization of obtained formulations was studied using different solvent-to-antisolvent volume ratios. In the entire optimization process, 3.5-6.5 acetone-water ratio formulation shows a good solid uniformsized nanoparticles. Hence, this formulation is used for further process.

\section{Optimization of drug concentration}

Different glimepiride solutions and atorvastatin calcium solutions were prepared in acetone in the concentration range of $10-60 \mathrm{mg} / \mathrm{ml}$ and $10-70 \mathrm{mg} / \mathrm{ml}$, respectively, which shows better resultant constant antisolvent ratio of glimepiride 3.5:6.5 and atorvastatin calcium 2.5:7.5.

Formulation of glimepiride nanosuspension and atorvastatin calcium nanosuspension

Glimepiride nanoparticle formulation GD-3 and GD-10 and atorvastatin calcium nanoparticles AC-4 and AC-9 show lowest particle size using 3.5:6.5 and 2.5:7.5 antisolvent ratio and the drug concentration was $40 \mathrm{mg} / \mathrm{ml}$ and $60 \mathrm{mg} / \mathrm{ml}$, respectively. Thus, these formulations were used for further process.

\section{Lyophilization of nanosuspension}

Lowest particle sized formulations of glimepiride (GD-3 and GD-10) and atorvastatin (AC-4 and AC-9) were added with different concentrations of mannitol and separately deep freezed.

\section{EVALUATION STUDIES}

\section{Percentage yield}

The results of percentage yield for the optimized formulations of glimepiride nanoparticles and atorvastatin calcium nanoparticles are listed in Tables 9 and 10.

\section{Particle size and size distribution}

The formulation of lyophilized glimepiride nanoparticle and atorvastatin calcium nanoparticle formulation was further investigated for particle size and particle size distribution using SEM. The best obtained result is given in Tables 11 and Figs. 3 and 4.

\section{Drug content}

The prepared glimepiride nanoparticle formulations were analyzed and the data are reported in Table 12. Drug content of glimepiride in nano-sized dry powder exhibited good uniformity. Drug content was well above $92 \%$, which showed that the drug was uniformly distributed with excipients in both the formulations.

Similarly, for atorvastatin calcium nanoparticles, the prepared formulations were analyzed for drug content and the data are reported in Table 13. Drug content of atorvastatin calcium in nano-sized dry

\section{Table 11: Particle size and size distribution}

\begin{tabular}{lll}
\hline Sample & Particle size (nm)* & PDI* $^{*}$ \\
\hline Glimepiride API & $8.3 \pm 0.18$ & $0.775 \pm 0.004$ \\
Atorvastatin calcium API & $18.5 \pm 0.32$ & $0.947 \pm 0.002$ \\
\hline
\end{tabular}

${ }^{*}$ mean \pm SD n=3, PDI: Polydispersity index, API: Active pharmaceutical ingredient

Table 12: Drug content of different glimepiride nanoparticle formulations

\begin{tabular}{ll}
\hline Formulation code & \% Drug content $(\mathbf{w} / \mathbf{w})^{*}$ \\
\hline GD-3d & $94.1 \pm 0.8$ \\
GD-10f & $93.6 \pm 1.2$ \\
\hline
\end{tabular}

${ }^{*}$ mean \pm SD $n=3$

Table 13: Drug content of different atorvastatin calcium nanoparticle formulations

\begin{tabular}{ll}
\hline Formulation code & \% Drug content $(\mathbf{w} / \mathbf{w})^{*}$ \\
\hline AC- $4 \mathrm{~d}$ & $91.9 \pm 1.1$ \\
AC-9c & $93.8 \pm 1.4$ \\
\hline
\end{tabular}

*mean \pm SD $n=3$

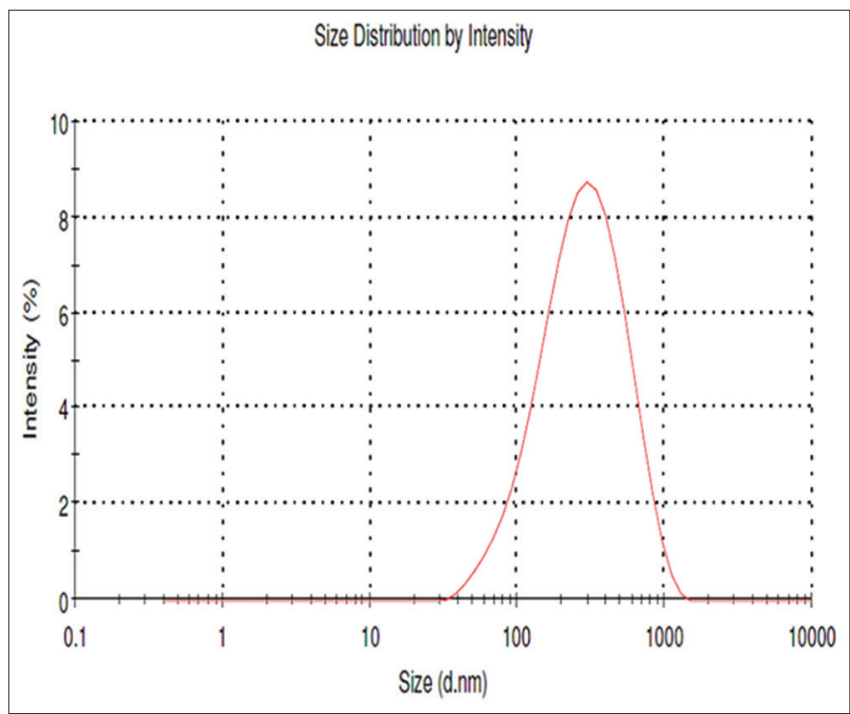

Fig. 3: Particle size of the lyophilized glimepiride nanoparticle formulation batch GD-3d

powder exhibited good uniformity. Drug content was well above 92\%, which showed that the drug was uniformly distributed with excipients in both the formulations. 
XRD studies

The X-ray diffractogram of glimepiride API and its formulation GD-3d and GD-10f is correlated in Fig. 5. The characteristic sharp and intense peaks of glimepiride API were found at $2 \theta$ angles of 10.84, 11.70, 18.92, $20.96,23.06$, and $27.26^{\circ}$, indicating its crystalline nature. However, the glimepiride nanosized formulation GD-3d and GD-10f exhibited peaks at similar position to glimepiride API but with reduced intensities, which can be attributed to lower crystallinity and smaller particle size of the glimepiride nanoparticles.

The X-ray diffractogram of atorvastatin calcium API and its formulation AC-4d and AC-9c is correlated in Fig. 6. The characteristic

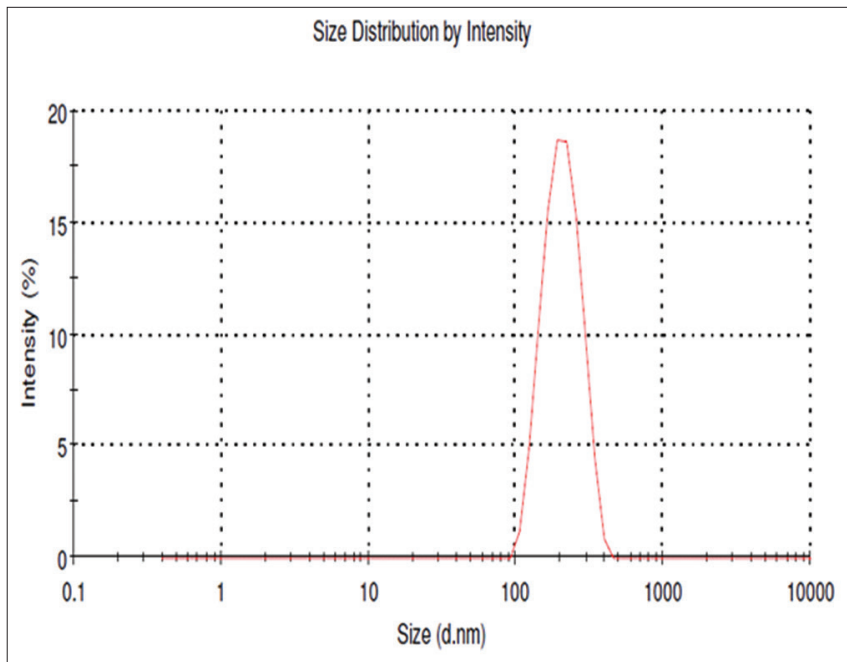

Fig. 4: Particle size of the lyophilized atorvastatin calcium nanoparticle formulation batch AC-4d sharp and intense peaks of atorvastatin calcium API were found at $2 \theta$ angles of $9.06,9.40,10.24,10.38,11.90,12.10,17.10,19.44$, $21.52,22.62,23.28,23.70$, and $29.04^{\circ}$, indicating its crystalline nature. However, for atorvastatin calcium nanosized formulations AC- $4 \mathrm{~d}$ and AC-9c, instead of those intense crystalline peaks, only one broad and diffuse maxima peak was detected, which indicated that the nanosized atorvastatin calcium was converted into amorphous form.

\section{In vitro drug release}

The dissolution profile for the combination of unprocessed glimepiride and atorvastatin calcium drug particles and combinations of processed drug particles of glimepiride and atorvastatin calcium is shown in Tables 14 and 15 and Figs. 7 and 8.

This dissolution enhancement can be explained by reduced particle size by LAS precipitation (LAS) processed particles. The LAS process decreased the size of particle to the nanometer range and concurrently increased the surface area of particles dramatically. The high energy state achieved by the increase in the surface area of particles can increase to an extent to which the particle can dissolve due to an increase in dissolution pressure in regard to Ostwald-Freundlich and Noyes-Whitney equations. Hence, due to higher saturation solubility, the fixed dose combination of nanosized, glimepiride formulation GD-3d and atorvastatin calcium formulation AC-4d, was considered for further pharmacokinetic studies.

\section{In vivo studies}

The mean plasma concentration-time profile of glimepiride API coadministered with atorvastatin calcium API and nanosized glimepiride formulation (GD-3d) coadministered with nanosized atorvastatin calcium formulation (AC-4d) is shown in Table 16 and Fig. 9, and the corresponding pharmacokinetic parameters are summarized in Table 17.

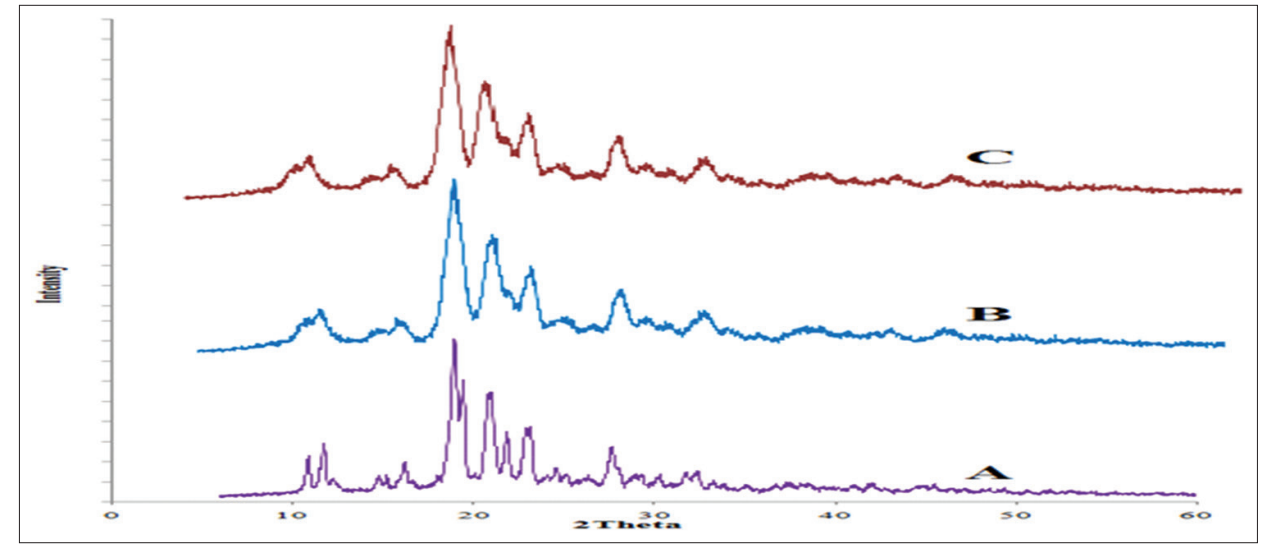

Fig. 5: X-ray diffraction of: (A) glimepiride active pharmaceutical ingredient; (B) formulation GD-3d; and (C) formulation GD-10f

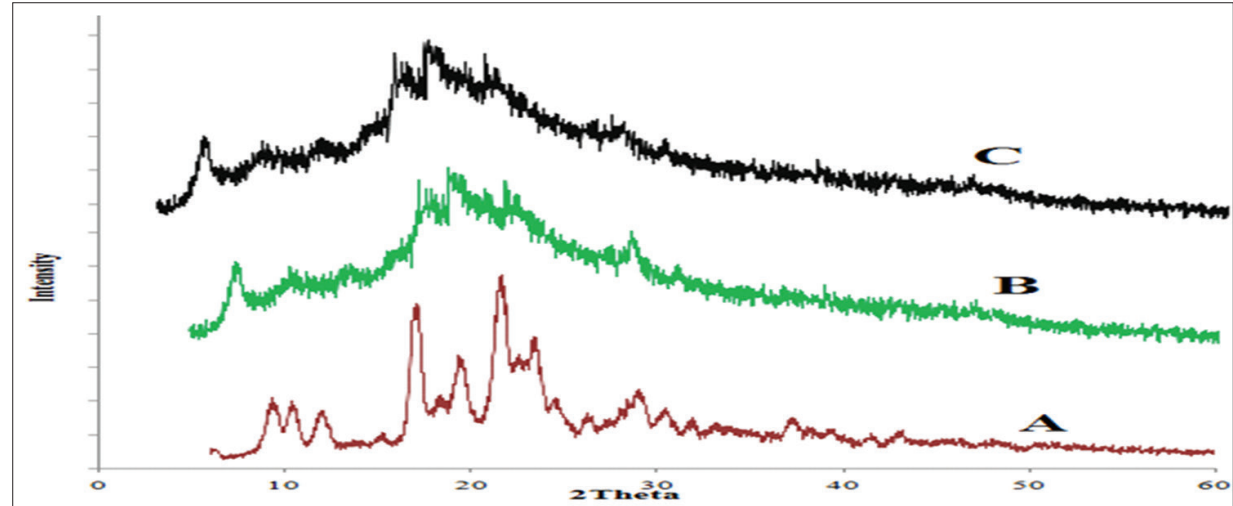

Fig. 6: X-ray diffraction of: (A) atorvastatin calcium active pharmaceutical ingredient; (B) formulation AC-4d; and (C) formulation AC-9c 
The oral absorption from fixed dose combination of nanosized glimepiride formulation GD-3d and atorvastatin calcium formulation $\mathrm{AC}-4 \mathrm{~d}$ was found higher when compared to their respective combination of unprocessed drugs. The smaller particle size of glimepiride powder and the amorphous nature of atorvastatin calcium powder along with nanosized particles might have allowed for higher apparent solubility, thereby increasing the concentration of drugs available for oral absorption

Table 14: In-vitro dissolution data of optimized glimepiride nanosized formulations and glimepiride API

\begin{tabular}{|c|c|c|c|}
\hline \multirow[t]{3}{*}{ Time (min) } & \multicolumn{3}{|l|}{ Formulation code } \\
\hline & \multicolumn{3}{|c|}{ Drug release $(\%)\left(\right.$ mean $\left.\pm S^{*}\right)$} \\
\hline & Glimepiride API & GD-3d & GD-10f \\
\hline 5 & $3.6 \pm 0.36$ & $69.5 \pm 1.82$ & $43.4 \pm 1.68$ \\
\hline 10 & $6.1 \pm 0.69$ & $78.3 \pm 2.31$ & $54.8 \pm 1.46$ \\
\hline 15 & $9.5 \pm 0.80$ & $85.7 \pm 2.08$ & $65.5 \pm 2.43$ \\
\hline 20 & $12.7 \pm 1.33$ & $95.2 \pm 1.67$ & $77.3 \pm 2.01$ \\
\hline 25 & $16.5 \pm 1.12$ & $97.4 \pm 1.94$ & $82.7 \pm 1.88$ \\
\hline 30 & $17.44 \pm 1.45$ & $98.5 \pm 2.39$ & $86.4 \pm 2.69$ \\
\hline 35 & $20.9 \pm 1.27$ & $99.0 \pm 2.68$ & $92.8 \pm 2.42$ \\
\hline 40 & $22.8 \pm 1.35$ & $99.2 \pm 2.36$ & $96.3 \pm 2.31$ \\
\hline 45 & $24.6 \pm 1.37$ & $98.8 \pm 2.42$ & $98.5 \pm 2.46$ \\
\hline 60 & $26.9 \pm 1.29$ & $98.5 \pm 2.79$ & $98.2 \pm 2.35$ \\
\hline 80 & $29.6 \pm 1.52$ & $98.2 \pm 2.59$ & $98.0 \pm 1.98$ \\
\hline 100 & $31.4 \pm 1.32$ & $97.7 \pm 1.95$ & $97.4 \pm 2.07$ \\
\hline 120 & $33 \pm 1.19$ & $97.4 \pm 1.82$ & $97.1 \pm 1.73$ \\
\hline
\end{tabular}

*mean \pm SD n=3, API: Active pharmaceutical ingredient

Table 15: In vitro dissolution data of optimized atorvastatin calcium nanosized formulations and atorvastatin calcium API

\begin{tabular}{|c|c|c|c|}
\hline \multirow[t]{3}{*}{ Time (min) } & \multicolumn{3}{|l|}{ Formulation code } \\
\hline & \multicolumn{3}{|c|}{ Drug release $(\%)\left(\right.$ mean $\left.\pm \mathrm{SD}^{*}\right)$} \\
\hline & Atorvastatin calcium API & AC-4d & AC-9c \\
\hline 5 & $13.4 \pm 0.71$ & $77.7 \pm 2.28$ & $58.5 \pm 1.84$ \\
\hline 10 & $16.8 \pm 0.94$ & $87.2 \pm 1.74$ & $74.3 \pm 2.50$ \\
\hline 15 & $19.5 \pm 0.86$ & $94.1 \pm 1.85$ & $80.1 \pm 2.31$ \\
\hline 20 & $24.7 \pm 1.03$ & $98.4 \pm 1.96$ & $89.4 \pm 1.95$ \\
\hline 25 & $27.4 \pm 1.29$ & $99.2 \pm 2.62$ & $96.3 \pm 1.88$ \\
\hline 30 & $28.3 \pm 1.15$ & $99.6 \pm 2.46$ & $98.8 \pm 2.76$ \\
\hline 35 & $29.5 \pm 1.67$ & $99.8 \pm 2.11$ & $99.6 \pm 2.49$ \\
\hline 40 & $31.2 \pm 1.43$ & $98.9 \pm 2.04$ & $99.8 \pm 2.55$ \\
\hline 45 & $35.8 \pm 1.76$ & $98.1 \pm 2.37$ & $99.2 \pm 2.41$ \\
\hline 60 & $38.6 \pm 1.26$ & $97.7 \pm 1.97$ & $98.7 \pm 1.95$ \\
\hline 80 & $41.5 \pm 1.39$ & $97.4 \pm 1.81$ & $98.2 \pm 1.78$ \\
\hline 100 & $44.1 \pm 1.81$ & $97.1 \pm 2.19$ & $97.6 \pm 2.04$ \\
\hline 120 & $44.8 \pm 1.55$ & $96.5 \pm 2.56$ & $97.1 \pm 2.16$ \\
\hline
\end{tabular}

*mean \pm SD n=3, API: Active pharmaceutical ingredient, SD: Standard deviation
The relative bioavailability of glimepiride formulation GD-3d and atorvastatin calcium formulation AC-4d was found to be 2.59 and 4.24 folds higher as compared to their unprocessed pure drugs. Hence, the optimized nanosized powders of glimepiride and atorvastatin calcium were able to increase the oral bioavailability of their respective drugs.

The $\mathrm{C}_{\max }$ and $\mathrm{AUC}_{0-24 \mathrm{~h}}$ of optimized glimepiride nanosized formulation GD-3d was found to be $24451.14 \pm 2170.5 \mathrm{ng} / \mathrm{ml}$ and $162945.12 \pm 241.5 \mathrm{ng} / \mathrm{ml}$, higher than that of unprocessed glimepiride API $(9428.42 \pm 897.8 \mathrm{ng} / \mathrm{ml}$ and $65106.41 \pm 60.3 \mathrm{ng} / \mathrm{ml})$. Similarly, the $\mathrm{C}_{\mathrm{m}}$ and $\mathrm{AUC}_{0-24 \mathrm{~b}}$ of optimized atorvastatin calcium formulation AC-4d were found to be $1385.43 \pm 153.3 \mathrm{ng} / \mathrm{ml}$ and $3636.57 \pm 65.2 \mathrm{ng} / \mathrm{ml}$, higher than that of unprocessed atorvastatin calcium API $(326.07 \pm 68.4 \mathrm{ng} / \mathrm{ml}$ and $2383.34 \pm 78.8 \mathrm{ng} / \mathrm{ml}$ ), respectively.

\section{Stability studies}

Stability studies of optimized fixed dose combination formulation of nanosized glimepiride (GD-3d batch) and atorvastatin calcium (AC- $4 \mathrm{~d}$ batch) were carried out at $25 \pm 2{ }^{\circ} \mathrm{C} / 60 \pm 5 \% \mathrm{RH}$ and $4 \pm 3^{\circ} \mathrm{C}$. The formulations were subjected to various evaluation parameters such as physical appearance, particle size, PDI, and drug content. The results are given in Tables 18 and 19. From the results, it can be confirmed that there were no significant changes in physicochemical properties of optimized nanosized glimepiride (GD-3d batch) and atorvastatin calcium (AC-4d batch) formulations when stored at $4 \pm 3^{\circ} \mathrm{C}$

However, the samples stored at room temperature have shown a significant increase in particle size and PDI, which can be attributed to Ostwald ripening phenomenon, where small particles dissolve and molecules redeposited to form large particles, with no significant change in physical appearance and drug content.

\section{SUMMARY AND CONCLUSION}

Formulation of glimepiride and atorvastatin calcium drug nanoparticles shows an increase in the surface-to-volume ratio of API, resulting in better drug solubility and hence increasing the bioavailability when compared to its pure form.

The in vitro dissolution results reveal which processed of the drug particles of glimepiride and atorvastatin showed significantly higher release compared to the unprocessed particles. In the in vivo studies, of nanosized glimepiride and atorvastatin showed higher $\mathrm{C}_{\max }$ and AUC than the unprocessed drugs.

\section{AUTHOR'S CONTRIBUTIONS}

Author is a faculty in division of pharmaceutics and the work contributed on faculty development in the institution. All the authors discussed the results and contributed to the final manuscript.

Table 16: Mean plasma concentrations-time data of glimepiride API, nanosized formulation GD-3d, atorvastatin calcium API and nanosized formulation AC-4d

\begin{tabular}{lllll}
\hline \multirow{2}{*}{ Time (h) } & \multicolumn{5}{l}{ Plasma drug concentration $(\mathbf{n g} / \mathbf{m l}) *$} & Formulation AC-4d \\
\cline { 2 - 5 } & Glimepiride API & Formulation GD-3d & Atorvastatin calcium API & $322.41 \pm 44.8$ \\
& $1153.21 \pm 317.6$ & $3371.08 \pm 586.6$ & $131.33 \pm 37.2$ & $1384.43 \pm 153.3$ \\
1 & $2484.40 \pm 381.4$ & $7035.50 \pm 774.8$ & $325.07 \pm 68.4$ & $729.59 \pm 103.4$ \\
1.5 & $3628.33 \pm 431.6$ & $11045.32 \pm 1234.2$ & $304.24 \pm 62.2$ & $545.64 \pm 87.1$ \\
2 & $5367.84 \pm 649.5$ & $15785.71 \pm 1698.4$ & $289.85 \pm 48.1$ & $376.15 \pm 63.1$ \\
4 & $9429.42 \pm 897.8$ & $24455.14 \pm 2170.5$ & $217.57 \pm 53.4$ & $195.37 \pm 37.3$ \\
6 & $6271.74 \pm 765.7$ & $162134.53 \pm 1702.1$ & $175.31 \pm 41.2$ & $102.23 \pm 29.4$ \\
12 & $3104.11 \pm 558.1$ & $9143.83 \pm 1063.4$ & $95.17 \pm 28.7$ & $25.05 \pm 9.7$ \\
16 & $1963.46 \pm 392.3$ & $3748.23 \pm 613.7$ & $23.76 \pm 11.8$ & $13.52 \pm 3.1$ \\
\hline 4
\end{tabular}

*mean \pm SD n=6, API: Active pharmaceutical ingredient 


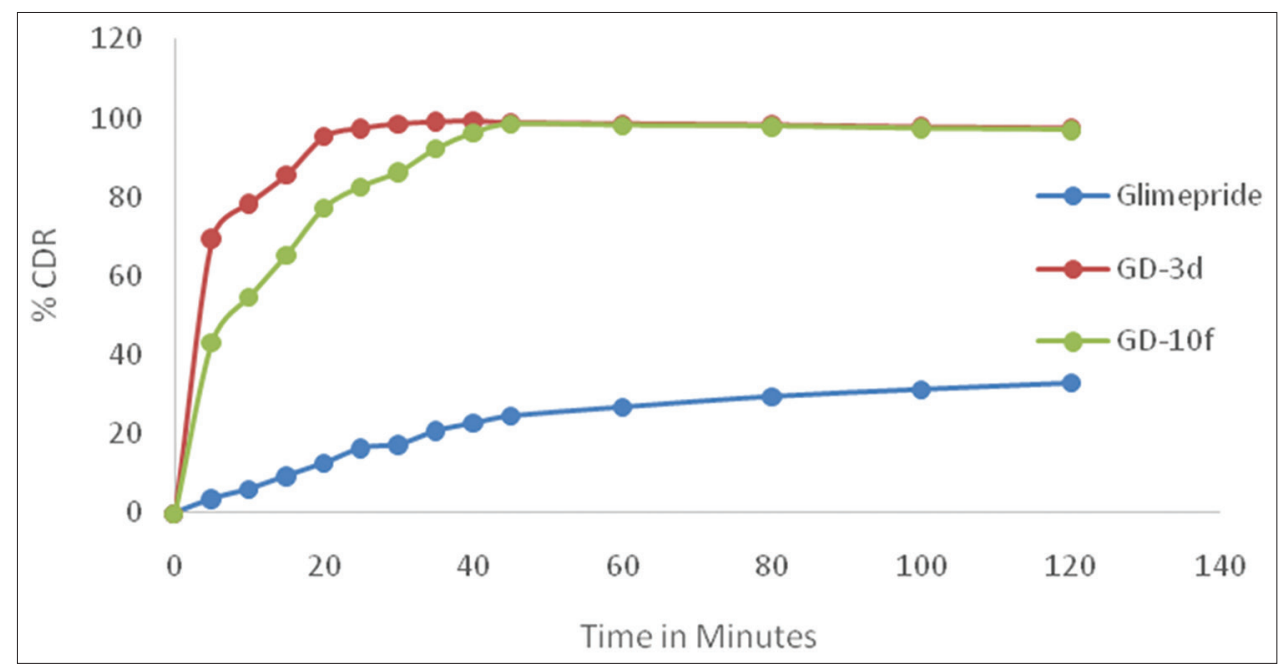

Fig. 7: In vitro drug release profile of optimized glibenclamide nanosized formulations and glibenclamide active pharmaceutical ingredient

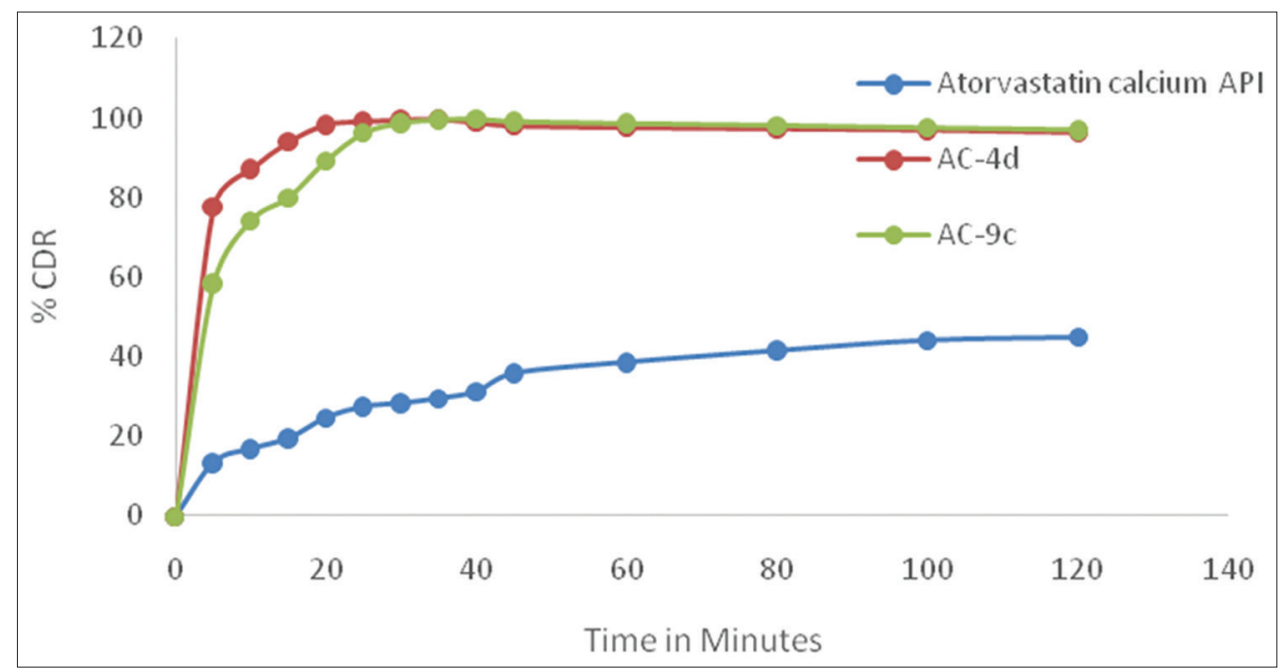

Fig. 8: In vitro drug release profile of optimized atorvastatin calcium nanosized formulations and atorvastatin calcium active pharmaceutical ingredient

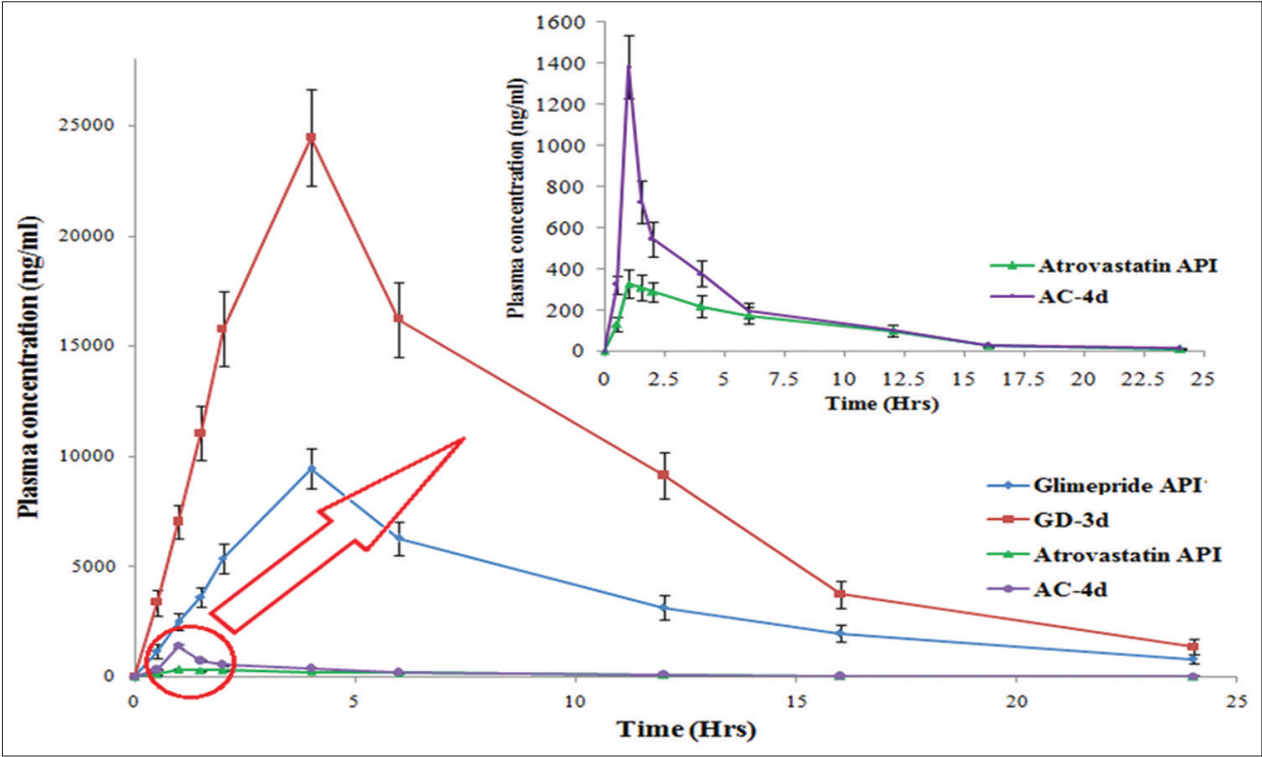

Fig. 9: Plasma drug concentration versus time profile 
Table 17: Pharmacokinetic parameters

\begin{tabular}{llllll}
\hline Parameters* & $\mathbf{C}_{\max }(\mathbf{n g} / \mathbf{m L})$ & $\mathbf{T}_{\max }(\mathbf{h})$ & $\mathbf{t}_{\mathbf{1 / 2}} \mathbf{( h )}$ & $\mathbf{K}_{\mathrm{el}}\left(\mathbf{h}^{-\mathbf{1}}\right)$ & $\mathbf{A U C}_{\mathbf{0} \rightarrow \mathbf{2 4 h}}(\mathbf{n g ~ h} / \mathbf{m L})$ \\
\hline Glimepiride API & $9427.42 \pm 897.8$ & $4.0 \pm 0.0$ & $5.73 \pm 0.42$ & $0.1207 \pm 0.0061$ & $65116.41 \pm 60.3$ \\
Formulation GD-3d & $24452.14 \pm 2170.5$ & $4.0 \pm 0.0$ & $9.57 \pm 0.23$ & $0.1438 \pm 0.0042$ & $162944.12 \pm 241.5$ \\
Atorvastatin calcium API & $325.07 \pm 68.4$ & $1.0 \pm 0.0$ & $4.79 \pm 0.16$ & $0.1585 \pm 0.0038$ & $2382.34 \pm 78.8$ \\
Formulation AC-4d & $1385.43 \pm 153.3$ & $1.0 \pm 0.0$ & $3.81 \pm 0.11$ & $0.1947 \pm 0.0084$ & $3632.57 \pm 65.2$ \\
\hline
\end{tabular}

${ }^{*}$ mean \pm SD n=6, API: Active pharmaceutical ingredient

Table 18: Stability study data for the optimized fixed dose formulation of nanosized glimepiride (GD-3d) and atorvastatin calcium (AC-4d) at $4 \pm 3^{\circ} \mathrm{C}$

\begin{tabular}{|c|c|c|c|c|c|}
\hline \multirow[t]{3}{*}{ Sampling interval (months) } & \multicolumn{5}{|l|}{$4 \pm 3^{\circ} \mathrm{C}$} \\
\hline & \multirow[t]{2}{*}{ Physical appearance } & \multirow[t]{2}{*}{ Particle Size (nm)* } & \multirow[t]{2}{*}{ PDI* } & \multicolumn{2}{|c|}{ Drug content $(\%)^{*}$} \\
\hline & & & & GD-3d & AC-4d \\
\hline 0 & White color & $163.9 \pm 6.2$ & $0.254 \pm 0.002$ & $97.7 \pm 1.8$ & $96.6 \pm 1.2$ \\
\hline 3 & No change & $174.2 \pm 5.8$ & $0.264 \pm 0.002$ & $98.6 \pm 2.1$ & $99.1 \pm 1.6$ \\
\hline 6 & No change & $169.4 \pm 7.3$ & $0.245 \pm 0.003$ & $96.5 \pm 2.6$ & $97.5 \pm 2.2$ \\
\hline
\end{tabular}

${ }^{*}$ mean \pm SD n=3, PDI: Polydispersity index

Table 19: Stability study data for the optimized fixed dose formulation of nanosized glimepiride (GD-3d) and atorvastatin calcium (AC-4d) at $25 \pm 2^{\circ} \mathrm{C}$ and $60 \pm 5 \% \mathrm{RH}$

\begin{tabular}{|c|c|c|c|c|c|}
\hline \multirow[t]{3}{*}{ Sampling interval (months) } & \multicolumn{5}{|l|}{$25 \pm 2^{\circ} \mathrm{C}$ and $60 \pm 5 \% \mathrm{RH}$} \\
\hline & \multirow[t]{2}{*}{ Physical appearance } & \multirow[t]{2}{*}{ Particle Size (nm)* } & \multirow[t]{2}{*}{ PDI* } & \multicolumn{2}{|c|}{ Drug content $(\%)^{*}$} \\
\hline & & & & GD-3d & $A C-4 d$ \\
\hline 0 & White color & $167.7 \pm 8.6$ & $0.262 \pm 0.002$ & $98.4 \pm 1.7$ & $98.2 \pm 2.2$ \\
\hline 3 & No change & $236.6 \pm 14.8$ & $0.298 \pm 0.003$ & $97.5 \pm 2.4$ & $98.9 \pm 1.9$ \\
\hline 6 & No change & $745.5 \pm 26.4$ & $0.662 \pm 0.04$ & $99.2 \pm 3.4$ & $99.7 \pm 2.8$ \\
\hline
\end{tabular}

*mean \pm SD n=3, PDI: Polydispersity index

\section{CONFLICTS OF INTEREST}

The author confirms that this article content has no conflicts of interest.

\section{REFERENCES}

1. Koczkur KM, Mourdikoudis S, Polavarapu L, Skrabalak SE. Polyvinylpyrrolidone (PVP) in nanoparticle synthesis. Dalton Trans 2015;44:17883-905.

2. Ige PP, Baria RK, Gattani SG. Fabrication of fenofibrate nanocrystals by probe sonication method for enhancement of dissolution rate and oral bioavailability. Colloids Surf B Biointerfaces 2013;108:366-73.

3. About diabetes. World Health Organization. Archived From the Original on 31 March 2014.

4. Pfizer Product Promotion Page (Lipitor)

5. Jogala S, Ankathi L, Jarupula RN. Glimepiride fast disintegrating tablets: Formulation, evaluation and in vivo disintegration and dynamic studies. Int J Pharm Pharm Sci 2016;8:271-8.

6. Behera A, Srikanth P, Rao YM, Sahoo SK. Formulation and characterisation of glimepiride loaded biodegradable nanoparticles for the management of Type 2 diabetes mellitus. Immunol Endocr Metab Agents in Med Chem (Formerly Current Medicinal ChemistryImmunology, Endocrine and Metabolic Agents) 2016;16:49-60.

7. Ramadan AA, Mandil H, Sabouni J. Determination of atorvastatin calcium in pure and its pharmaceutical formulations using iodine in acetonitrile by Uv-visible spectrophotometric method. Int $\mathrm{J}$ Pharm
Pharm Sci 2015;7:427-33

8. Zhang HX, Wang JX, Zhang ZB, Le Y, Shen ZG, Chen JF, et al. Micronization of atorvastatin calcium by antisolvent precipitation process. Int J Pharm 2009;374:106-13.

9. Sola D, Rossi L, Schianca GP, Maffioli P, Bigliocca M, Mella R, et al. Sulfonylureas and their use in clinical practice. Arch Med Sci 2015;11:840-8.

10. Kim MS, Jin SJ, Kim JS, Park HJ, Song HS, Neubert RH, et al. Preparation, characterization and in vivo evaluation of amorphous atorvastatin calcium nanoparticles using supercritical antisolvent (SAS) process. Eur J Pharm Biopharm 2008;69:454-65.

11. Geinsen K. Special pharmacology of the new sulfonylurea glimepiride. Drug Res 1988;38:1120-30.

12. Rabinow BE. Nanosuspensions in drug delivery. Nat Rev Drug Discov 2004;3:785-96.

13. Lennernäs $H$. Clinical pharmacokinetics of atorvastatin. Clin Pharmacokinet 2003;42:1141-60.

14. Kawabata Y, Wada K, Nakatani M, Yamada S, Onoue S. Formulation design for poorly water-soluble drugs based on biopharmaceutics classification system: Basic approaches and practical applications. Int J Pharm 2011;420:1-0

15. Rasenack N, Müller BW. Micron-size drug particles: Common and novel micronization techniques. Pharm Dev Technol 2004;9:1-3.

16. Won DH, Kim MS, Lee S, Park JS, Hwang SJ. Improved physicochemical characteristics of felodipine solid dispersion particles by supercritical anti-solvent precipitation process. Int J Pharm 2005;301:199-208. 